\title{
Translational aspects of the novel object recognition task in rats abstinent following sub-chronic treatment with phencyclidine (PCP): effects of modafinil and relevance to cognitive deficits in schizophrenia
}

\section{John P. Redrobe*, Sascha Bull and Niels Plath}

Department of In Vivo Neuropharmacology, Valby, Denmark

\section{Edited by:}

Franco Borsini, Sigma-Tau Industrie

Farmaceutiche Riunite S.p.A., Italy

\section{Reviewed by:}

Jo C. Neill, University of Bradford, UK

Franco Borsini, Sigma-Tau Industrie

Farmaceutiche Riunite S.p.A., Italy

${ }^{*}$ Correspondence:

John P. Redrobe, Department of In Vivo

Neuropharmacology, H. Lundbeck A/S,

Ottiliavej 9, 2500 Valby, Denmark.

e-mail:jopr@/undbeck.com
Phencyclidine (PCP) induces a behavioral syndrome in rodents that bears remarkable similarities to some of the core symptoms observed in schizophrenic patients, among those cognitive deficits. The successful alleviation of cognitive impairments associated with schizophrenia (CIAS) has become a major focus of research efforts as they remain largely untreated. The aim of the present study was to investigate the effects of selected antipsychotic and cognition enhancing drugs, namely haloperidol, risperidone, donepezil, and modafinil in an animal model widely used in preclinical schizophrenia research. To this end, the novel object recognition (NOR) task was applied to rats abstinent following sub-chronic treatment with PCP. Rats were administered either PCP ( $5 \mathrm{mg} / \mathrm{kg}$, i.p.) or vehicle twice a day for 7 days, followed by a 7-day washout period, before testing in NOR. Upon testing, vehicle-treated rats successfully discriminated between novel and familiar objects, an effect abolished in rats that had previously been exposed to PCP treatment. Acute treatment with modafinil $(64 \mathrm{mg} / \mathrm{kg}$, p.o.) ameliorated the PCP-induced deficit in novel object exploration, whereas haloperidol $(0.1 \mathrm{mg} / \mathrm{kg}$, s.c.), risperidone $(0.2 \mathrm{mg} / \mathrm{kg}$, i.p.), and donepezil (3 mg/kg, p.o.) were without significant effect. Given the negligible efficacy of haloperidol and risperidone, and the contradictory data with donepezil to treat CIAS in the clinic, together with the promising preliminary pro-cognitive effects of modafinil in certain subsets of schizophrenic patients, the sub-chronic PCP-NOR abstinence paradigm may represent an attractive option for the identification of potential novel treatments for CIAS.

\section{INTRODUCTION}

Cognitive impairments in schizophrenia are among the core symptoms of the disease (Sharma and Antonova, 2003), they correlate with functional outcome (Fett et al., 2010), and are not well treated with current antipsychotic therapies (Harvey and Keefe, 2001; Keefe et al., 2007a). In an attempt to align research efforts and aid the clinical evaluation of potential pro-cognitive therapeutics, the Measurement and Treatment Research to Improve Cognition in Schizophrenia (MATRICS) initiative has identified seven cognitive domains affected in schizophrenia; namely, attention/vigilance, working memory, reasoning and problem solving, processing speed, visual learning and memory, verbal learning and memory, and social cognition (Green et al., 2004). Subsequently, efforts have been made to use the MATRICS battery to guide development of a preclinical cognitive test battery for research in schizophrenia (Young et al., 2009).

One of the preclinical assays suggested useful by MATRICS is the novel object recognition (NOR) task (Ennaceur and Delacour, 1988), a test paradigm thought to reflect visual learning and recognition processing (Young et al., 2009) that has been compared to, among others, the visual paired-comparison task in humans (Clark et al., 2000; Manns et al., 2000). Moreover, schizophrenia patients show deficits in 2-D object recognition tasks very similar to the NOR paradigm (Clare et al., 1993; Aleman et al.,
1999; Heckers et al., 2000; Tek et al., 2002), which is of importance for the task's validity in relation to preclinical studies of schizophrenia.

Enormous efforts have been made, not least by employing various pharmacological interventions, to mimic some of the clinically observed symptomatology in rodents (Neill et al., 2010; O'Tuathaigh and Waddington, 2010; Wilson et al., 2010). One such strategy, the sub-chronic administration of PCP, induces a behavioral and neurobiological syndrome in rodents upon cessation of treatment that bears a remarkable similarity to some of the core symptoms in schizophrenic patients, including cognitive disruption (Jentsch and Roth, 1999). There is substantial evidence implicating an important role for $\mathrm{N}$-methyl-D-aspartate receptors (NMDARs) in learning and memory processing and that NMDAR function is aberrant in schizophrenia (Jentsch and Roth, 1999). NMDAR antagonists, such as ketamine and PCP, exacerbate psychosis in schizophrenia patients, and induce schizophrenia-like symptoms in healthy volunteers (Lahti et al., 1995; Hetem et al., 2000; Honey et al., 2005). Some of the behavioral effects of PCP in humans have been shown to persist for several weeks following treatment cessation, which has been the impetus for exploring abstinence from repeated PCP administration as a pharmacological animal model with some relevance to schizophrenia (Jentsch and Roth, 1999; Enomoto et al., 2007; Seillier and Giuffrida, 2009). One advantage of employing 
such a treatment-abstinence protocol is that animals are free from the acute motor effects of PCP that may otherwise hinder interpretation of data. Another is that simple pharmacological interactions that could account for reversal of drug-induced effects are avoided (Young et al., 2009). Specifically, such a treatment regime has been repeatedly shown to disrupt preference for exploration of a novel object in the NOR task when animals are tested in an abstinent state (Damgaard et al., 2010; Idris et al., 2010; McLean et al., 2010; Snigdha et al., 2010). In addition, sub-chronic PCP administration has been demonstrated to reduce glucose utilization in the prefrontal cortex following termination of treatment (Pratt et al., 2008), suggesting hypofrontality. Such effects are accompanied by a reduction in markers of GABAergic interneurons (e.g., parvalbumin and Kv3.1 mRNA expression) (Abdul-Monim et al. 2007; Pratt et al., 2008), and deficits in cognitive domains (Goetghebeur and Dias, 2009; see Jentsch and Roth, 1999, for review).

Taken together, as the NOR task is generally accepted as an interesting behavioral assay for measuring cognitive performance, and the sub-chronic administration of PCP to rodents can be considered as an animal model possessing some validity with respect to schizophrenia-like symptomatology, we decided to test a collection of clinically validated compounds showing varying effects in humans (Harvey and Keefe, 2001; Turner et al., 2004; Keefe et al., 2007a; Stip et al., 2007; Ribeiz et al., 2010) in our model system. The aim of the present study was therefore to investigate the effects of the typical antipsychotic, haloperidol; the atypical antipsychotic, risperidone; the acetylcholinesterase inhibitor (AChEi), donepezil; and the wake-promoting agent, modafinil, in the NOR task in rats treated sub-chronically with PCP. The results are discussed with respect to published preclinical studies and clinical findings in schizophrenic patients.

\section{MATERIALS AND METHODS \\ ANIMALS}

Seventy-four adult male Lister Hooded rats (220-240 g at the time of testing) from Charles River (Germany), were housed four per cage under controlled conditions (12-h of light starting at 06:00;
$20 \pm 2{ }^{\circ} \mathrm{C} ; 30-70 \%$ humidity) in Macrolon (type III) cages with standard sawdust bedding and environmental enrichment (plastic house and wooden chew blocks), with food and water available ad libitum (except during habituation, acquisition and retention trials). All animal procedures were carried out in compliance with the European Commission Directive 86/609/EEC and with Danish law regulating experiments on animals.

\section{DRUGS AND TREATMENT}

Phencyclidine (synthesized in-house) at $5 \mathrm{mg} / \mathrm{kg}$ was diluted in $0.9 \%$ saline. Haloperidol, risperidone and donepezil (Sigma, Denmark) were dissolved in $0.9 \%$ saline to concentrations of $0.1,0.2$, and $3 \mathrm{mg} / \mathrm{kg}$, respectively. Modafinil (Sequoia Research Products, UK) was suspended in $0.5 \%$ methylcellulose (Sigma, Denmark) to a concentration of $64 \mathrm{mg} / \mathrm{kg}$.

Rats were administered sub-chronic PCP ( $5 \mathrm{mg} / \mathrm{kg}$ i.p. b.i.d. for 7 days) or saline ( $1 \mathrm{ml} / \mathrm{kg}$ i.p. b.i.d. for 7 days) at 7 am and $7 \mathrm{pm}$, followed by a 7-day washout period prior to behavioral testing. This treatment regime is in accordance with previous methods (see Egerton et al., 2005; Rodefer et al., 2005, 2008). Haloperidol (free-base, $0.1 \mathrm{mg} / \mathrm{kg}$, s.c.), risperidone (free-base, $0.2 \mathrm{mg} / \mathrm{kg}$ i.p.), donepezil (hydrochloride salt, $3 \mathrm{mg} / \mathrm{kg}$, p.o.), and modafinil (freebase, $64 \mathrm{mg} / \mathrm{kg}$, p.o.) were dosed $30 \mathrm{~min}$ prior to the acquisition trial (see Figure 1A). The doses of haloperidol and risperidone were chosen based on in-house in vivo $\mathrm{D}_{2}$ receptor occupancy studies (approximately 65\% at time of test session; data not shown), and previous published findings (Grayson et al., 2007). The doses of modafinil and donepezil were selected based on previous published findings (Waters et al., 2005; Sambeth et al., 2007; Goetghebeur and Dias, 2009). All doses are expressed as mg/kg free-base. All animals were randomly assigned to treatment groups.

\section{APPARATUS AND BEHAVIORAL TESTING}

Novel object recognition testing was performed in a rectangular arena surrounded by non-transparent plexi-glass walls (dimensions: $95 \times 45 \times 50 \mathrm{~cm}$ ). The arena was placed on a down-flow
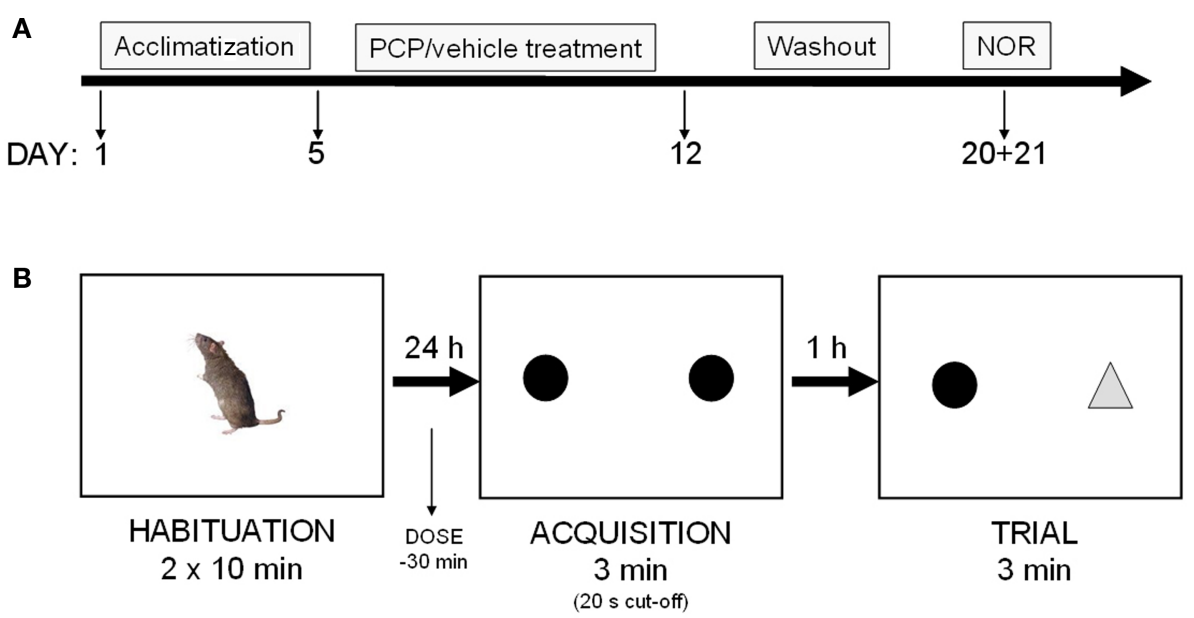

FIGURE 1 | (A) Experimental schedule: rats were treated for 7 days with vehicle or PCP (5 mg/kg, IP, b.i.d) before a 7-day washout period. Rats were then exposed to the novel object recognition paradigm (NOR), on days $8+9$ following last PCP injection. (B) NOR: rats were treated with vehicle or test compound as outlined in the "Materials and Methods" section, and the time spent exploring a novel and familiar object was measured. 
air table (for ventilation) and was surrounded by a black curtain. Animals were habituated to the empty arena in groups of four in $2 \times 10$ min sessions on day 1 . On day 2 , individual animals were introduced to the arena for an acquisition session with two identical objects (two opaque Perspex pyramids, $10 \times 10 \times 6 \mathrm{~cm}$, or two domed glass paperweights, $8 \times 8 \times 8 \mathrm{~cm}$ ) for $3 \mathrm{~min}$ (or until $20 \mathrm{~s}$ total active object exploration was achieved). The animals were then transferred to their homecages for a $1 \mathrm{~h}$ inter-trial interval (ITI). Following this period, the animal was re-introduced into the arena for the test session. Here, a triplicate of the familiar and a novel object were placed in the arena and the animal was allowed to explore during a 3-min test session. A camera mounted above the arena relayed the animal's general behavior (e.g., distance traveled) to a computer equipped with Ethovision tracking software (Noldus, UK), and object interaction was scored manually by an experimenter blinded to the dose groups. Object exploration was defined as sniffing, licking or touching the object while facing it. Animals that did not reach a total exploration time of $15 \mathrm{~s}$, after exploring both objects for a minimum of $2 \mathrm{~s}$, were excluded from the data analysis. All testing was performed on day 8 or 9 after the last PCP injection (see Figure 1B). Treatment groups/subjects and novel/familiar object identity and location were randomized across experiments.

\section{DATA PRESENTATION AND STATISTICAL ANALYSIS}

Data is presented as: (i) exploration time (s) of novel or familiar object; (ii) total exploration time of novel and familiar object (s); (iii) discrimination index (DI), calculated as the novel object exploration time $\left(T_{\mathrm{n}}\right)$ minus the familiar object exploration time $\left(T_{\mathrm{f}}\right)$ divided by the total exploration time $\left(T_{\mathrm{n}}+T_{\mathrm{f}}\right)$; (iv) total distance traveled $(\mathrm{cm})$. Two experiments were performed separately under identical conditions $(\mathrm{V}+\mathrm{V}, \mathrm{PCP}+\mathrm{V}, \mathrm{PCP}+$ modafinil, $\mathrm{PCP}+$ donepezil and $\mathrm{V}+\mathrm{V}, \mathrm{PCP}+\mathrm{V}, \mathrm{PCP}+$ haloperidol, $\mathrm{PCP}+$ risperidone). Statistical analysis (Student's $t$-test) was then performed to ensure that there was no significant difference between respective $\mathrm{V}+\mathrm{V}$-treated groups, and also between respective $\mathrm{PCP}+\mathrm{V}$-treated groups. This was indeed the case and the data from the two separate experiments were then pooled and one-way ANOVA, followed by appropriate all pair-wise multiple comparison post hoc analysis (Bonferroni's $t$-test) was used to investigate statistical differences between test groups $(P<0.05)$.

\section{RESULTS}

Three animals from the vehicle + haloperidol-treated group, and two animals from the vehicle + modafinil-treated group, did not meet the inclusion criteria and were excluded from the data analysis (i.e., 5 rats out of 74 total).

Analysis of exploration time of novel and familiar objects showed a statistically significant group effect (one-way ANOVA, $F(11,212)=13.31, P<0.001)$. As shown in Figure 2, vehicle-treated rats spent more time exploring the novel over the familiar object during the 3 min retention trial $(P<0.001$, Bonferroni's multiple comparison). This effect was abolished in abstinent PCP-treated rats, which explored both objects to a similar degree. This indicates that 8- to 9-day washout following sub-chronic PCP treatment impairs object recognition capabilities at the $1 \mathrm{~h}$ ITI. Acute treatment with modafinil (64 mg/kg), $30 \mathrm{~min}$ before the acquisition trial, ameliorated the PCP-induced deficit $(P<0.01$, Bonferroni's multiple comparison), whereas haloperidol $(0.1 \mathrm{mg} / \mathrm{kg})$, risperidone $(0.2 \mathrm{mg} / \mathrm{kg})$, and donepezil ( $3 \mathrm{mg} / \mathrm{kg}$ ) were without significant effect (Figure 2). Total exploration times did not significantly differ across treatment groups (Figure 3).

The preference scores for the objects can be further demonstrated by the DI, a relative measure that corrects the difference between novel/familiar object exploration for total exploration activity, and thus allows comparison between groups (Rutten et al., 2008). Analysis of DI scores revealed a statistically significant group effect (one-way ANOVA, $F(5,106)=20.62, P<0.001)$. Here, vehicle-treated animals displayed significantly higher index scores compared to abstinent

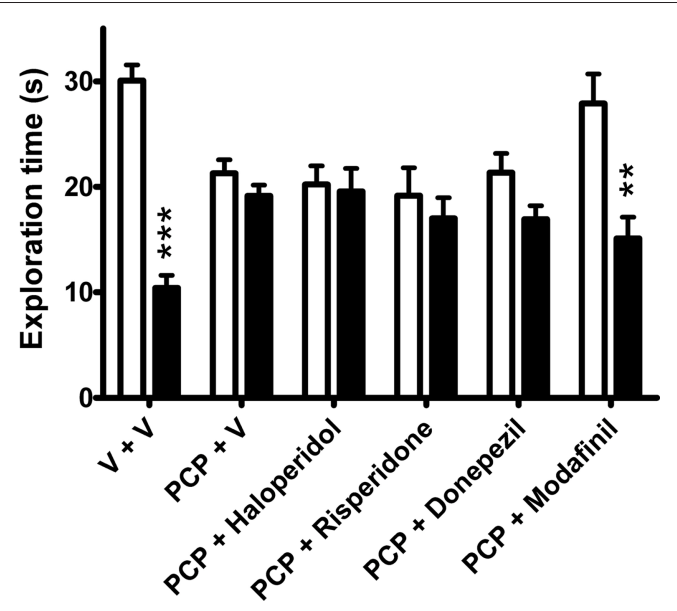

FIGURE 2 |The effects of vehicle $(n=31)$, haloperidol $(0.1 \mathrm{mg} / \mathrm{kg}, n=9)$, risperidone ( $0.2 \mathrm{mg} / \mathrm{kg}, n=12)$, donepezil ( $3 \mathrm{mg} / \mathrm{kg}, n=12)$, and modafinil (64 mg/kg, $n=10$ ) on exploration time (s) of a novel (open bars) and familiar (closed bars) object in the NOR task in rats subchronically treated with PCP $(\boldsymbol{n}=\mathbf{3 3})$. Data expressed as mean + SEM. ** $P<0.001,{ }^{*} P<0.01$ versus novel object exploration (one-way ANOVA followed by Bonferroni's multiple comparison post hoc analysis).

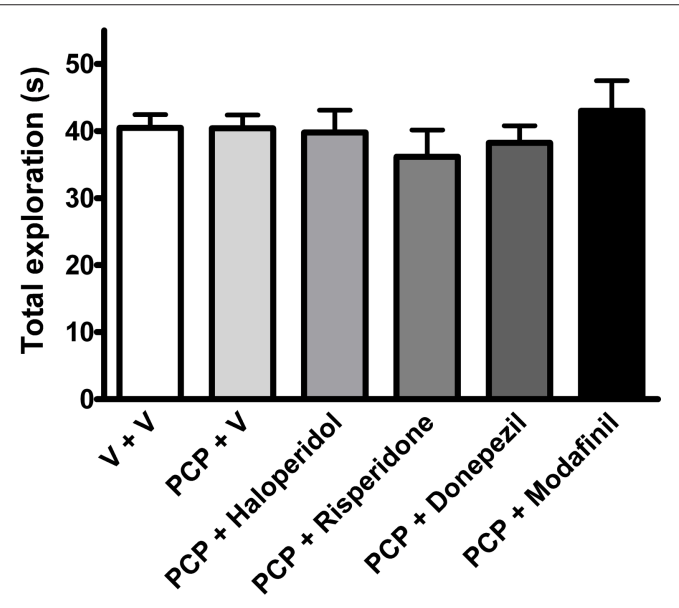

FIGURE 3 |The effects of vehicle ( $n=31)$, haloperidol $(0.1 \mathrm{mg} / \mathrm{kg}, n=9)$, risperidone $(0.2 \mathrm{mg} / \mathrm{kg}, n=12)$, donepezil ( $3 \mathrm{mg} / \mathrm{kg}, n=12)$, and modafinil (64 mg/kg, $n=10$ ) on total exploration time in the NOR task in rats sub-chronically treated with $\mathrm{PCP}(\boldsymbol{n}=\mathbf{3 3})$. Data expressed as mean + SEM. 
PCP-treated rats $(P<0.001$, Bonferroni's multiple comparison). Again, modafinil significantly attenuated PCP-induced deficits $(P<0.01$, Bonferroni multiple comparison), whereas haloperidol, risperidone or donepezil had no significant effect (Figure 4).

Analysis of total distance traveled during the 3-min retention trial revealed a statistically significant group effect (one-way ANOVA, $F(5,106)=6.91, P<0.001)$. As shown in Figure 5, haloperidol and risperidone-treated groups traveled significantly shorter distances during the 3 -min retention trial, when compared to vehicle-treated animals $(P<0.001$ and $P<0.05$, respectively, Bonferroni's multiple comparison).

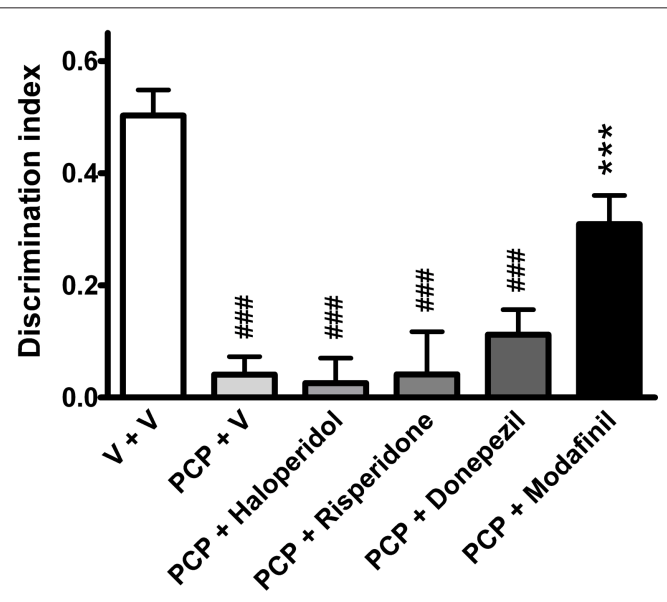

FIGURE 4 |The effects of vehicle $(n=31)$, haloperidol $(0.1 \mathrm{mg} / \mathrm{kg}, n=9)$, risperidone ( $0.2 \mathrm{mg} / \mathrm{kg}, n=12)$, donepezil ( $3 \mathrm{mg} / \mathrm{kg}, n=12)$, and modafinil $(64 \mathrm{mg} / \mathrm{kg}, n=10)$ on $\mathrm{DI}\left(T_{n}-T_{\mathrm{f}}\right) /\left(T_{\mathrm{n}}+T_{\mathrm{f}}\right)$ in the NOR task in rats sub-chronically treated with PCP $(\boldsymbol{n}=\mathbf{3 3})$. Data expressed as mean + SEM. \#\# $P<0.001$ versus vehicle-treated group; ${ }^{*} * P<0.001$ versus PCP-treated group (one-way ANOVA followed by Bonferroni's multiple comparison post hoc analysis).

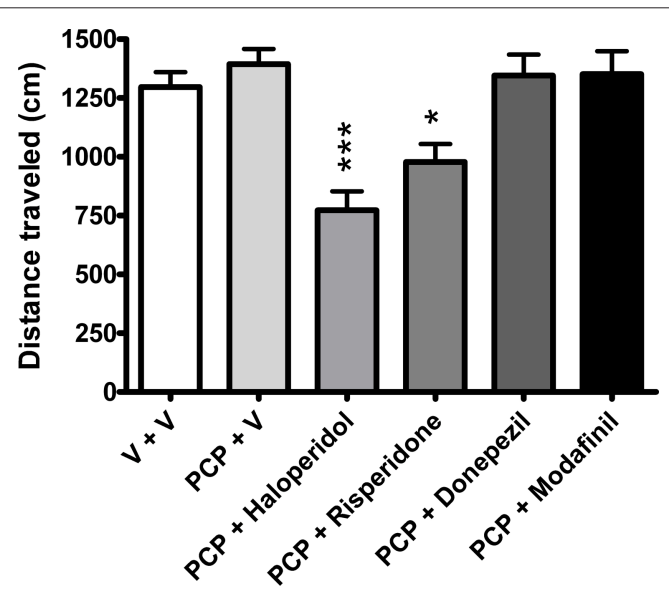

FIGURE 5 |The effects of vehicle $(n=31)$, haloperidol $(0.1 \mathrm{mg} / \mathrm{kg}, n=9)$, risperidone $(0.2 \mathrm{mg} / \mathrm{kg}, n=12)$, donepezil ( $3 \mathrm{mg} / \mathrm{kg}, n=12)$, and modafinil $(64 \mathrm{mg} / \mathrm{kg}, n=10)$ on distance traveled in the NOR task in rats sub-chronically treated with PCP $(\boldsymbol{n}=\mathbf{3 3})$. Data expressed as mean + SEM. ${ }^{* *} P<0.001,{ }^{*} P<0.05$ versus vehicle-treated group (one-way ANOVA followed by Bonferroni's multiple comparison post hoc analysis).

\section{DISCUSSION}

In the present study, we demonstrate that the wake-promoting agent, modafinil, possesses pro-cognitive potential when tested in the NOR task applied to a recognized animal model of schizophrenia. In accordance with previous studies (Damgaard et al., 2010; Idris et al., 2010; McLean et al., 2010; Snigdha et al., 2010), subchronic PCP treatment induced a significant memory impairment in the NOR task following a 1-h ITI in rats abstinent from PCP for 8-9 days. This deficit was attenuated by acute treatment with modafinil, whereas the antipsychotic drugs haloperidol and risperidone as well as the AChEi donepezil were without effect. Total object exploration times of objects during the retrieval phase did not differ across groups, although, haloperidol and risperidonetreated animals traveled a significantly shorter distance, which reflects reduced exploration of the arena rather than the objects. To our knowledge, this is the first report outlining pro-cognitive potential of modafinil in the NOR task in rats that have previously been sub-chronically treated with PCP, and underlines the suggested clinical utility of this drug for the treatment of discrete cognitive deficits in schizophrenia.

Pre-clinically, modafinil has displayed pro-cognitive-like activity in a number of behavioral assays thought to address a variety of cognitive domains in "normal" animals (see Minzenberg and Carter, 2008 for review). These effects have been mirrored in the clinical setting, where modafinil has been shown to improve performance in certain cognitive domains in non-sleep/sleep deprived healthy volunteers (Pigeau et al., 1995; Turner et al., 2003; Muller et al., 2004; Wesensten et al., 2005). However, pro-cognitive effects in animal models thought to reflect some aspects of a disease state are limited. In an eloquent study, modafinil displayed a favorable profile in the attentional set-shifting task in rats sub-chronically treated with PCP (Goetghebeur and Dias, 2009). This assay is thought to reflect prefrontal cortex functioning (Birrell and Brown, 2000), which is known to be compromised in schizophrenia patients presenting cognitive impairment (Patel et al., 2010). The present data agree with, and further extend these results and suggest that modafinil may also be of benefit to patients suffering from deficits in recognition memory processing together with impairments in executive function (Turner et al., 2004).

The precise mechanism of action of modafinil is a subject of debate. However, it has been reported that it leads to increases in central noradrenaline, dopamine, and histamine levels (Madras et al., 2006). Furthermore, modafinil decreases GABA in some regions, which maybe a consequence of its ability to increase central glutamate levels (see Kumar, 2008 for review). Thus, the neurochemical profile of modafinil would seem to fit with its potential to induce pro-cognitive effects.

Preclinical studies in the NOR task investigating the potential pro-cognitive activity of some currently available antipsychotics, e.g., risperidone, and the AChEi, donepezil, are somewhat conflicting with the data presented herein. For example, Grayson et al. (2007) reported that risperidone reversed a sub-chronic PCPinduced deficit in NOR at a dose identical to that employed in the present study. However, this study was performed using female Lister Hooded rats, as opposed to males, and employed an ITI of $1 \mathrm{~min}$, as opposed to $1 \mathrm{~h}$ as used in the present study. These methodological differences between studies could explain the disparity 
in the effects of risperidone. On the other hand, our data with haloperidol is in agreement with that of Grayson et al. (2007). Furthermore, Kunitachi et al. (2009) showed that donepezil was capable of reversing a sub-chronic PCP-induced deficit in NOR performance. However, this study was performed using male ICR mice, employed an ITI of $24 \mathrm{~h}$, and donepezil was administered once a day for 14 days, as opposed to an acute injection $30 \mathrm{~min}$ before acquisition used in the present study. A more recent study also outlined some positive effects of donepezil in an object-place-context recognition assay in rats sub-chronically treated with PCP (Le Cozannet et al., 2010). Donepezil was shown to improve performance in "normal" animals, and to attenuate PCP-induced deficits at a $5 \mathrm{~min}$, but not a $10 \mathrm{~min}$, ITI following chronic administration. Again, methodological differences between the studies could explain the discrepancies in the data. However, it cannot be ruled out that donepezil may have shown positive effects in the present study if a chronic treatment regimen had been employed.

Unfortunately, methodological differences across laboratories are a fact of life within preclinical research and demand either utilization of standardized protocols or introduction of additional control readouts that allow more stringent comparison between labs. Discrepancies in experimental set ups are not only confined to the preclinical laboratory, as now will be discussed with respect to clinical investigations.

Clinical studies investigating the potential pro-cognitive activity of typical (e.g., haloperidol) and atypical (e.g., risperidone) antipsychotics in schizophrenic patients have yielded negligible or no effects, in agreement with the present study. Thus, treatment with antipsychotic medication is associated with slight to moderate improvement in cognitive test performance of patients who have schizophreniform disorder, who are in their first episode of schizophrenia, or who are chronically ill (Harvey and Keefe, 2001; Keefe et al., 2007a; Davidson et al., 2009). In addition, the magnitude of improvement does not differ between treatment with haloperidol and treatment with second-generation antipsychotics. (Harvey and Keefe, 2001; Keefe et al., 2007a; Davidson et al., 2009). AChEIs have also been tested in initial clinical trials in schizophrenia, with some studies suggesting a moderate beneficial effect in general cognitive impairment when administered as an add-on treatment (Buchanan et al., 2003; Lee et al., 2007; Chung et al., 2009), while others showed no benefits (Friedman et al., 2002; Tugal et al., 2004; Keefe et al., 2007b). Therefore, it has been generally accepted that there is considerable room for improvement in the treatment of cognitive symptoms, and this is reflected in the amount of research being performed.

As a result of the encouraging preclinical data pointing toward a possible pro-cognitive effect of modafinil, several clinical studies in schizophrenic patients have been initiated with somewhat

\section{REFERENCES}

Abdul-Monim, Z., Neill, J. C., and Reynolds, G. P. (2007). Sub-chronic psychomimetic phencyclidine induces deficits in reversal learning and alterations in parvalbumin-immunoreactive expression in the rat. J. Pshychopharmacol. 21, 198-205.

Aleman, A., Hijman, R., de Haan, E. H., and Kahn, R. S. (1999). Memory impairment in schizophrenia: a meta-analysis. Am. J. Psychiatry 156, 1358-1366.

Birrell, J. M., and Brown, V. J. (2000). Medial frontal cortex mediates perceptual attentional set shifting in the rat. J. Neurosci. 20, 4320-4324.

Buchanan, R. W., Summerfelt, A., Tek, C., and Gold, J. (2003). An openlabeled trial of adjunctive donepezil

contradictory findings. A recent review gathered available data on clinical trials of modafinil treatment for cognitive deficits in schizophrenia (Saavedra-Velez et al., 2009). Of the six reviewed studies, three trials showed promising effects of modafinil in several cognitive domains, including recognition memory. Other domains benefiting from modafinil included short-term memory, working memory, attention, and executive function (Rosenthal and Bryant, 2004; Turner et al., 2004; Spence et al., 2005). Functional correlates, as assessed by imaging, were identified in two studies in discrete brain areas linked to working memory processing (Spence et al., 2005; Hunter et al., 2006). A potential concern was highlighted in three studies (Sevy et al., 2005; Spence et al., 2005; Pierre et al., 2007), where a slight propensity for psychosis exacerbation was observed $(6.0 \%$ versus $2.9 \%$ in modafinil- and placebo-treated groups, respectively). Two of these studies failed to show any cognitive benefit of modafinil (Sevy et al., 2005; Pierre et al., 2007).

It has been suggested that the positive effects of modafinil on cognitive processing, at least in healthy volunteers, maybe limited to "lower-performing" individuals (Muller et al., 2004), or to individuals with lower IQ (Randall et al., 2005). This may be an important observation with respect to the choice of schizophrenic patients to be included in clinical trials. A consideration could be that patients could be better segmented and only patients displaying cognitive deficits across similar domains should be included in clinical investigations, although it is understood that such a suggestion may infer considerably more work for the trial organizers in finding such patients. In addition, the inclusion of patients showing deficits in domains where modafinil has proven beneficial in preclinical models/assays could also serve to increase the likelihood of success. Overall, although the clinical data on modafinil looks encouraging across several cognitive domains, the preliminary nature of the studies to date, i.e., small sample sizes together with methodological differences between trials, make it difficult to draw firm conclusions.

In summary, given the negligible efficacy of haloperidol and risperidone, the contradictory data with donepezil to treat cognitive symptoms associated with schizophrenia in the clinic (Harvey and Keefe, 2001; Keefe et al., 2007a), and the promising preliminary pro-cognitive effects of modafinil in certain subsets of schizophrenic patients (Morein-Zamir et al., 2007), the subchronic PCP-NOR abstinence paradigm may represent an attractive option for the identification of potential novel treatments. Only with well-powered, randomized placebo-controlled trials incorporating validated test batteries, and in connection with global functional outcome measures, will modafinil's efficacy and effectiveness as a treatment for cognitive deficits in schizophrenia be confirmed.

for cognitive impairments in patients with schizophrenia. Schizophr. Res. 59, 29-33.

Clare, L., McKenna, P. J., Mortimer, A. M. and Baddeley,A. D. (1993). Memory in schizophrenia: What is impaired and what is preserved? Neuropsychologia 31, 1225-1241.

Clark, R. E., Zola, S. M., and Squire, L. R. (2000). Impaired recognition memory in rats after damage to the hippocampus. J. Neurosci. 20, 8853-8860.

Chung, Y.C., Lee, C. R., Park, T. W., Yang, K. H., and Kim, K.W. (2009). Effect of donepezil added to atypical antipsychotics on cognition in patients with schizophrenia: an open-label trial. World J. Biol. Psychiatry 10, 156-162. 
Damgaard, T., Larsen, D. B., Hansen, S. L., Grayson, B., Neill, J. C., and Plath N. (2010). Positive modulation of alpha-amino-3-hydroxy-5-methyl4-isoxazolepropionic acid (AMPA) receptors reverses sub-chronic PCPinduced deficits in the novel object recognition task in rats. Behav. Brain Res. 207, 144-150.

Davidson, M., Galderisi, S., Weiser, M., Werbeloff, N., Fleischhacker, W. W., Keefe, R. S., Boter, H., Keet, I. P., Prelipceanu, D., Rybakowski, J. K., Libiger, J., Hummer, M., Dollfus, S., López-Ibor, J.J., Hranov, L. G., Gaebel, W., Peuskens, J., Lindefors, N., RiecherRössler, A., and Kahn, R. S. (2009). Cognitive effects of antipsychotic drugs in first-episode schizophrenia and schizophreniform disorder: a randomized, open-lable clinical trial (EUfEST). Am. J. Psychiatry 166, 675-682.

Egerton, A., Reid, L., McKerchar, C. E., Morris, B. J., and Pratt, J. A. (2005). Impairment in perceptual attentional set-shifting following PCP administration: a rodent model of set-shifting deficits in schizophrenia. Psychopharmacology 179, 77-84.

Ennaceur, A., and Delacour, J. (1988). A new one-trial test for neurobiological studies of memory in rats. 1: behavioural data. Behav. Brain Res. $31,47-59$.

Enomoto, T., Noda, Y., and Nabeshima, T. (2007). Phencyclidine and genetic animal models of schizophrenia developed in relation to the glutamate hypothesis. Methods Find. Exp. Clin. Pharmacol. 29, 291-301.

Fett, A. K., Viechtbauer, W., Dominguez, M. D., Penn, D. L., van Os, J., and Krabbendam, L. (2010). The relationship between neurocognition and social cognition with functional outcomes in schizophrenia: a metaanalysis. Neurosci. Biobehav. Rev. doi: 10.1016/j.neubiorev.2010.07.001.

Friedman, J. I., Adler, D. N., Howanitz, E., Harvey, P. D., Brenner, G., Temporini, H., White, L., Parrella, M., and Davis, K. L. (2002). A double blind placebo controlled trial of donepezil adjunctive treatment to risperidone for the cognitive impairment of schizophrenia. Biol. Psychiatry 51, 349-357.

Goetghebeur, P., and Dias, R. (2009). Comparison of haloperidol, risperidone, sertindole, and modafinil to reverse an attentional set-shifting impairment following subchronic PCP administration in the rat: a back translational study. Pyschopharmacology 202, 287-293.

Grayson, B., Idris, N. F., and Neill, J. C. (2007). Atypical antipsychotics attenuate a sub-chronic PCP-induced cognitive deficit in the novel object recognition task in the rat. Behav. Brain Res. 184, 31-38.

Green, M. F., Nuechterlein, K. H., Gold, J. M., Barch, D. M., Cohen, J., Essock, S., Fenton, W. S., Frese, F., Goldberg, T. E., Heaton, R. K., Keefe, R. S., Kern, R. S., Kraemer, H., Stover, E., Weinberger, D. R., Zalcman, S., and Marder, S. R. (2004). Approaching a consensus cognitive battery for clinical trials in schizophrenia: the NIMH-MATRICS conference to select cognitive domains and test criteria. Biol. Psychiatry 56, 301-307.

Harvey, P. D., and Keefe, R. S. E. (2001). Studies of cognitive change in patients with schizophrenia following novel antipsychotic treatment. Am. J. Psychiatry 158, 176-184.

Heckers, S., Curran, T., Goff, D., Rauch, S. L., Fischman, A. J., Alpert, N. M., and Schacter, D. L. (2000). Abnormalities in the thalamus and prefrontal cortex during episodic object recognition in schizophrenia. Biol. Psychiatry 48, 651-657.

Hetem, L.A., Danion, J.M., Diemunsch, P., and Brandt, C. (2000). Effect of a subanesthetic dose of ketamine on memory and conscious awareness in healthy volunteers. Psychopharmacology 152, 283-288.

Honey, G. D., Honey, R. A., Sharar, S. R., Turner, D. C., Pomarol-Clotet, E., Kumaran, D., Simons, J. S., Hu, X., Rugg, M. D., Bullmore, E. T., and Fletcher, P. C. (2005). Impairment of specific episodic memory processes by sub-psychotic doses of ketamine: the effects of levels of processing at encoding and of the subsequent retrieval task. Psychopharmacology 181, 445-457.

Hunter, M. D., Ganesan, V., Wilkinson, I. D., and Spence, S. A. (2006). Impact of modafinilon prefrontal executive function in schizophrenia. Am. J. Psychiatry 163, 2184-2186.

Idris, N., Neill, J., Grayson, B., BangAndersen, B., Witten, L. M., Brennum, L. T., and Arnt, J. (2010). Sertindole improves sub-chronic PCP-induced reversal learning and episodic memory deficits in rodents: involvement of $5-\mathrm{HT}(6)$ and $5-\mathrm{HT}(2 \mathrm{~A})$ receptor mechanisms. Psychopharmacology 208, 23-36.

Jentsch, J. D., and Roth, R. H. (1999). The neuropsychopharmacology of phencyclidine: from NMDA receptor hypofunction to the dopamine hypothesis of schizophrenia. Neuropsychopharmacology 20, 201-225.

Keefe, R. S., Bilder, R. M., Davis, S. M., Harvey, P. D., Palmer, B. W., Gold, J. M., Meltzer, H. Y., Green, M. F.,
Capuano, G., Stroup, T. S., McEvoy, J. P., Swartz, M. S., Rosenheck, R. A., Perkins, D. O., Davis, C.E., Hsiao, J. K. Lieberman, J.A., CATIE Investigators, and Neurocognitive Working Group (2007a). Neurocognitive effects of antipsychotic medications in patients with chronic schizophrenia in the CATIE trial. Arch. Gen. Psychiatry 64 633-647.

Keefe, R. S., Malhotra, A. K., Meltzer, H. Y., Kane, J. M., Buchanan, R. W., Murthy, A., Sovel, M., Li, C., and Goldman, R. (2007b). Efficacy and safety of donepezil in patients with schizophrenia or schizoaffective disorder: significant placebo//practice effects in a 12 -week, randomized, double-blind, placebo-controlled trial. Neuropsychopharmacology 33, 1217-1228.

Kumar,R. (2008). Approved and investigational uses of modafinil: an evidencebased review. Drugs 68, 1803-1839.

Kunitachi, S., Fujita, Y., Ishima, T., Kohno, M., Horio, M., Tanibuchi, Y., Shirayama, Y., Iyo, M., and Hashimoto, K. (2009). Phencyclidine-induced cognitive deficits in mice are ameliorated by subsequent subchronic administration of donepezil: role of sigma-1 receptors. Brain Res. 1279, 189-196.

Lahti, A., Koffel, B., LaPorte, D., and Tamminga, C. A. (1995). Subanesthetic doses of ketamine stimulate psychosis in schizophrenia. Neuropsychopharmacology 13, 9-19.

Le Cozannet, R., Fone, K. C., and Moran, P. M. (2010). Phencyclidine withdrawal disrupts episodic-like memory in rats: reversal by donepezil but not clozapine. Int. J. Neuropsychopharmacol. 13 , 1011-1020.

Lee, B. J., Lee, J. G., and Kim, Y.H. (2007). A 12-week, double-blind, placebo-controlled trial of donepezil as an adjunct to haloperidol for treating cognitive impairments in patients with chronic schizophrenia. J. Psychopharmacol. 21 , 421-427.

Madras, B. K., Xie, Z., Lin, Z., Jassen, A., Panas, H., Lynch, L., Johnson, R., Livni, E., Spencer, T. J., Bonab, A. A., Miller, G. M., and Fischman, A. J. (2006). Modafinil occupies dopamine and norepinephrine transporters in vivo and modulates transporters and trace amine activity in vitro. J. Pharmacol. Exp. Ther. 319, 561-569.

Manns, J. R., Stark, C. E. L., and Squire, L. R. (2000). The visual paired-comparison task as a measure of declarative memory. Proc. Natl. Acad. Sci. U.S.A. 97, 12375-12379.

McLean, S. L., Grayson, B., Idris, N F., Lesage, A. S., Pemberton, D. J., Mackie, C., and Neill, J. C. (2010). Activation of alpha7 nicotinic recep- tors improves phencyclidine-induced deficits in cognitive tasks in rats: implications for therapy of cognitive dysfunction in schizophrenia. Eur. Neuropsychopharmacol. doi: 10.1016/j. neuroeuro.2010.06.003.

Minzenberg, M. J., and Carter, C. S. (2008). Modafinil: a review of neurochemical actions and effects on cognition. Neuropsychopharmacology 33, 1477-1502.

Morein-Zamir, S., Turner, D. C., and Sahakian, B. J. (2007). A review of the effects of modafinil on cognition in schizophrenia. Schizophr. Bull. 33, 1298-1306.

Müller, U., Steffenhagen, N., Regenthal, R., and Bublak, P. (2004). Effects of modafinil on working memory processes in humans. Psychopharmacology 177, 161-169.

Neill, J. C., Barnes, S., Cook, S., Grayson, B., Idris, N. F., McLean, S. L., Snigdha, S., Rajagopal, L., and Harte, M. K. (2010). Animal models of cognitive dysfunction and negative symptoms of schizophrenia: focus on NMDA receptor antagonism. Pharmacol. Ther. doi: 10.1016/j.pharmthera.2010.07.004.

O'Tuathaigh, C. M., and Waddington, J. L. (2010). Mutant mouse models: phenotypic relationships to domains of psychopathology and pathobiology in schizophrenia. Schizophr. Bull. 36, 243-245.

Patel, N. H., Vyas, N. S., Puri, B. K., Nijran, K. S., and Al-Nahhas, A. (2010) Positron emission tomography in scizophrenia: a new perspective. J. Nucl. Med.51, 511-520.

Pierre, J. M., Peloian, J. H., Wirshing, D. A., Wirshing, W. C., and Marder, S. R. (2007). A randomized, double-blind, placebo-controlled trial of modafinil for negative symptoms in schizophrenia. J. Clin. Psychiatry 68, 705-710.

Pigeau, R., Naitoh, P., Buguet, A., McCann, C., Baranski, J., Taylor, M., Thompson, M., and Mack, II. (1995). Modafinil, $\mathrm{d}$-amphetamine and placebo during $64 \mathrm{~h}$ of sustained mental work. I. Effects on mood, fatigue, cognitive performance and body temperature. J. Sleep Res. 4, 212-228.

Pratt, J. A., Winchester, C., Egerton, A., Cochran, S. M., and Morris, B. J. (2008). Modelling prefrontal cortex deficits in schizophrenia: implications for treatment. Br. J. Pharmacol. 153(Suppl. 1), S465-S470.

Randall, D. C., Shneerson, J. M., and File, S. E. (2005). Cognitive effects of modafinil in student volunteers may depend on IQ. Pharmacol. Biochem. Behav. 82, 133-139.

Ribeiz, S. R., Bassitt, D. P., Arrais, J. A., Avila, R., Steffens, D. C., and Bottino, C. M. (2010). Cholinesterase inhibi- 
tors as adjunctive therapy in patients with schizophrenia and schizoaffective disorder: a review and metaanalysis of the literature. CNS Drugs 24, 303-317.

Rodefer, J.S., Murphy, E. R., and Baxter, M. G. (2005).PDE10A inhibition reverses PCP-induced deficits in attentional set-shifting in rats. Eur. J. Neurosci. 21, 1070-1076.

Rodefer, J. S., Nguyen, T. N., Karlsson, J. J., and Arnt, J. (2008). Reversal of subchronic PCP-induced deficits in attentional set shifting in rats by sertindole and a 5-HT6 receptor antagonist: comparison among antipsychotics. Neuropsychopharmacology 33, 2657-2666.

Rosenthal, M.H., and Bryant, S. L. (2004). Benefits of adjunct modafinil in an open-label, pilot study in patients with schizophrenia. Clin. Neuropharmacol. 27, 38-43.

Rutten, K., Reneerkens, O. A., Hamers, H., Sik, A., McGregor, I. S., Prickaerts, J., and Blokland, A. (2008). Automated scoring of novel object recognition in rats. J. Neurosci. Methods 171, 72-77.

Saavedra-Velez, C., Yusim, A., Anbarasan, D., and Lindenmayer, J. P. (2009). Modafinil as an adjunctive treatment of sedation, negative symptoms, and cognition in schizophrenia: a critical review. J. Clin. Psychiatry 70, 104-112. Sambeth, A., Riedel, W. J., Smits, L. T., and Blokland,A. (2007). Cholinergic drugs affect novel object recognition in rats: relation with hippocampal EEG? Eur. J. Pharmacol. 572, 151-159.
Seillier, A., and Giuffrida, A. (2009). Evaluation of NMDA receptor models of schizophrenia: divergences in the behavioral effects of sub-chronic PCP and MK-801. Behav. Brain Res. 204, 410-415.

Sevy, S., Rosenthal, M. H., Alvir, J., Meyer, S., Visweswaraiah, H., Gunduz-Bruce, H., and Schooler, N. R. (2005). Doubleblind, placebo-controlled study of modafinil for fatigue and cognition in schizophrenic patients treated with psychotropic medications. J. Clin. Psychiatry 66, 839-843.

Sharma, T., and Antonova, L. (2003). Cognitive function in schizophrenia: deficits, functional consequences, and future treatment. Psychiatr. Clin. North Am. 26, 25-40.

Snigdha, S., Horiguchi, M., Huang, M., Li, Z., Shahid, M., Neill, J. C., and Meltzer, H. Y. (2010). Attenuation of phencyclidine-induced object recognition deficits by the combination of atypical antipsychotic drugs and pimivanserin (ACP 103), a 5-hydroxytryptamine(2A) receptor inverse agonist. J. Pharmacol. Exp. Ther. 332, 622-631.

Spence, S.A., Green, R. D., Wilkinson, I.D., and Hunter, M. D. (2005). Modafinil modulates anterior cingulated function in chronic schizophrenia. Br. J. Psychiatry 187, 55-61.

Stip, E., Sepehry, A. A., and Chouinard, S. (2007). Add-on therapy with acetylcholinesterase inhibitors for memory dysfunction in schizophrenia: a systematic quantitative review, part 2. Clin. Neuropharmacol. 30, 218-229.
Tek, C., Gold, J., Blaxton, T., Wilk, C., McMahon, R. P., and Buchanan, R. W. (2002). Visual perceptual and working memory impairments in schizophrenia. Arch. Gen. Psychiatry 59, 146-153.

Tuğal, O., Yazici, K. M., Anil Yağcioğlu, A. E., and Göğüğ, A. (2004). A doubleblind, placebo controlled, cross-over trial of adjunctive donepezil for cognitive impairment in schizophrenia. Int. J. Neuropsychopharmacol. 7, 117-123.

Turner, D. C., Robbins, T. W., Clark, L., Aron, A. R., Dowson, J., and Sahakian, B. J. (2003). Cognitive enhancing effects of modafinil in healthy volunteers. Psychopharmacology 165, 260-269.

Turner, D. C., Clark, L., Pomarol-Clotet, E., McKenna, P., Robbins, T. W., and Sahakian, B. J. (2004). Modafinil improves cognition and attentional set shifting in patients with chronic schizophrenia. Neuropsychopharmacology 29, 1363-1373.

Waters, K. A., Burnham, K. E., O'Connor, D., Dawson, G. R., and Dias, R. (2005). Assessment of modafinil on attentional processes in a five-choice serial reaction time test in the rat. $J$. Psychopharmacol. 19, 149-158.

Wesensten, N. J., Killgore, W. D., and Balkin, T. J. (2005). Performance and alertness of caffeine, dextroamphetamine, and modafinil during sleep deprivation. J. Sleep Res. 14, 255-266.

Wilson, C., and Terry, A. V. Jr. (2010). Neurodevelopmental animal mod- els of schizophrenia: role in novel drug discovery and development. Clin. Schizophr. Relat. Psychoses 4, 124-137.

Young, J. W., Powell, S. B., Risbrough, V., Marston, H. M., and Geyer, M. A. (2009). Using the MATRICS to guide development of a preclinical cognitive test battery for research in schizophrenia. Pharmacol. Ther. 122, 150-202.

Conflict of Interest Statement: The authors declare that the research was conducted in the absence of any commercial or financial relationships that could be construed as a potential conflict of interest.

Received: 10 September 2010; paper pending published:30 September 2010; accepted: 15 October 2010; published online: 11 November 2010.

Citation: Redrobe JP, Bull S and Plath N (2010) Translational aspects of the novel object recognition task in rats abstinent following sub-chronic treatment with phencyclidine (PCP): effects of modafinil and relevance to cognitive deficits in schizophrenia Front. Psychiatry 1:146. doi: 10.3389/ fpsyt.2010.00146

This article was submitted to Frontiers in Psychopharmacology, a specialty of Frontiers in Psychiatry.

Copyright (c) 2010 Redrobe, Bull and Plath. This is an open-access article subject to an exclusive license agreement between the authors and the Frontiers Research Foundation, which permits unrestricted use, distribution, and reproduction in any medium, provided the original authors and source are credited. 